\title{
Thermal diffusion and molecular diffusion values for some alkane mixtures: A comparison between thermogravitational column and thermal diffusion forced Rayleigh scattering
}

\author{
Pablo Blanco, ${ }^{1, *}$ Pavel Polyakov, ${ }^{2, \dagger}$ M. Mounir Bou-Ali ${ }^{\ddagger},{ }_{\S}$ and Simone Wiegand ${ }^{\llbracket 2, * *}$ \\ ${ }^{1}$ MGEP Mondragon Goi Eskola Politeknikoa, Manufacturing \\ Department. Loramendi 4 Apdo. 23, 20500 Mondragon, Spain. \\ ${ }^{2}$ Forschungszentrum Jülich GmbH, \\ IFF - Weiche Materie, D-52428 Jülich, Germany
}

(Dated: April 17, 2008)

\begin{abstract}
In the present work we studied the thermal diffusion behavior of $n$-decane in various alkanes by thermogravitational column (TC) techniques and thermal diffusion forced Rayleigh scattering (TDFRS) method. The investigated lighter alkanes compared to $n$-decane are $n$-pentane, $n$ hexane, $n$-heptane, $n$-octane and the heavier ones are $n$-tetradecane, $n$-pentadecane, $n$-hexadecane, $n$-heptadecane, $n$-octadecane and $n$-eicosane. The binary mixture $n$-decane $/ n$-pentane we investigated at several different concentrations all other mixtures were only investigated at a mass fraction of $50 \%$. Even for the volatile $n$-pentane/n-decane mixture the deviations between the thermal diffusions coefficients determined by the different methods agreed within the error bars. Typically the agreement between the two methods was in the order of $5 \%$. Compared to recently published TC and TDFRS data we found deviations in the order of 30 up to $40 \%$. We analyze and discuss the possible reasons for the discrepancies for the present and the past publications.
\end{abstract}

PACS numbers:

\footnotetext{
$\ddagger$ corresponding author

ฯ corresponding author
} 


\section{INTRODUCTION}

The coupling between a temperature gradient and a resulting mass flux is denoted thermal diffusion or Ludwig-Soret effect in accordance with its discover and its first investigator. Particularly, the investigation of crude oil components such as alkanes and organic ring compounds is of practical relevance, because the determination of reliable model parameters is essential for the characterization of geological fields. ${ }^{1-3}$ Additionally the effect plays also an important role in separation techniques for liquid mixtures (see e.g. Refs. [4-7]).

In the simple case of a binary mixture with constant pressure there is a mass diffusion current $j_{\mathrm{D}}=-\rho D \nabla c$ and a thermal diffusion current $j_{\mathrm{T}}=-\rho D_{\mathrm{T}} c(1-c) \nabla T$, with $c$ the mass fraction, $\rho$ the density of the liquid, and $D$ and $D_{\mathrm{T}}$ the mutual mass and thermal diffusion coefficients, respectively. In the stationary state the two flows cancel and the resulting concentration gradient is given by

$$
\nabla c=-S_{\mathrm{T}} c(1-c) \nabla T
$$

$S_{\mathrm{T}}=D_{\mathrm{T}} / D$ is the Soret coefficient.

The thermal diffusion of non-polar fluid mixtures is sometimes governed by the mass, size, and shape of the molecules as well as their interactions (see Ref. [7] for a review). The influence of the physical parameters on the thermal diffusion behavior has been systematically investigated for isotopic mixtures of benzene and cyclohexane. ${ }^{8,9}$ For these mixtures it was found that the Soret coefficient depends on the mass and moment of inertia difference but also on a chemical contribution. In the case of polar mixtures, specific interactions between the molecules dominate the thermal diffusion process while mass and size are not so important.

A number of studies have focused on the Soret effect in mixtures containing an alkane as one of the components. Different experimental techniques were applied to investigate the thermal diffusion behavior of toluene/hexane, ${ }^{10-12}$ alkane/alkane, ${ }^{13-15}$ cyclohexane/benzene, ${ }^{8}$ and $n$-alkane/benzene ${ }^{12,16-21}$ mixtures. Also in a benchmark study of three binaries one of the components was an alkane. ${ }^{22}$ In the past also thermodynamic models ${ }^{23}$ have been tested and simulations ${ }^{13}$ have been performed for alkane mixtures.

Alkanes belong to the class of non-polar mixtures. Often they are treated as ideal mixtures, because the minor microscopic effects, such as the conformational changes in 
the molecules have only a very small effect on the usual thermodynamic properties of alkane/alkane mixtures. This tendency is also confirmed in a recent thermal diffusion study of alkane/alkane mixture, ${ }^{14,15}$ which shows that always the heavier component moves to the cold region. On the other hand minor microscopic effects contribute significantly to entropic and enthalpic thermodynamic properties. ${ }^{24}$ Those deviations from ideality of linear alkanes are for instance also reflected in larger excess enthalpies compared to branched alkanes. ${ }^{25}$ This might also be reason for the observation that the heavier linear alkanes in equimolar mixtures of alkane/benzene mixtures tend to move to the warm side, while the highly branched alkanes accumulate at the cold side and show a more normal behavior. ${ }^{21}$ If one uses the rule of the thumb that the denser component moves to the cold side the situation is reversed, because for example the density of heptane and its isomers is lower than the density of benzene, while the mass of benzene is larger than the mass of heptane. In order to complicate the situation even more 2,2,4-trimethylpentane an isomer of octane in benzene shows even a sign change with concentration.

We focus in this work on the Soret effect in binary alkane/alkane mixtures for which we expect a normal behavior. All mixtures are investigated by thermogravitational column (TC) technique and thermal diffusion forced Rayleigh scattering (TDFRS) method. First we investigate the binary mixture $n$-decane/ $n$-pentane at several different concentration at $27^{\circ} \mathrm{C}$. This mixture we studied even with a cylindrical and parallelepipedic thermogravitational column. The experimental data are compared with earlier experimental data and simulation results. ${ }^{13}$ Additionally, we investigated binary mixtures of $n$-decane in $n$-hexane, $n$-heptane, $n$-octane, $n$-tetradecane, $n$-pentadecane, $n$-hexadecane, $n$-heptadecane, $n$-octadecane and $n$ eicosane at a weight fraction of $50 \%$. The obtained experimental data are also compared with recent measurementy by the TC method. ${ }^{15}$

\section{EXPERIMENT}

\section{A. Sample preparation}

\section{Thermogravitational columns:}

All the products used in the TCs were purchased from Merck with a purity better than 99\%. First we always filled in the less volatile component, i.e., the alkane with higher 
molecular weight; then the corresponding amount of the second alkane is added. The concentrations of the binary mixtures were adjusted by weighting both components separately. The mixtures for the parallelepipedic TC were prepared with a balance with a capacity up to $310 \mathrm{~g}$ and an accuracy of $0.0001 \mathrm{~g}$. For the mixtures of the cylindrical TC we used a balance with a capacity up to $4500 \mathrm{~g}$ and an accuracy of $0.01 \mathrm{~g}$. The sample volume needed to run an experiment in the parallelepipedic and cylindrical TC is approximately $25 \mathrm{~cm}^{3}$ and 300 $\mathrm{cm}^{3}$, respectively. As verification, before and after each experimental run the concentration of the mixture had been determined. The observed concentration change was typically in the order of $\Delta c_{0}=0.0005$.

\section{TDFRS:}

The alkanes $n$-pentane $(\geqslant 99 \%), \quad n$-hexane $(\geqslant 99 \%), \quad n$-heptane $(\geqslant 99.5 \%), \quad n$-octane $(\geqslant 99.5 \%), n$-octadecane $(\geqslant 99 \%)$ and $n$-tetradecane $(\geqslant 99 \%)$ were purchased from Fluka; $n$ decane $(\geqslant 99 \%)$, $n$-heptadecane $(99 \%)$ and $n$-eicosane (99\%) were ordered from Aldrich. The alkane mole fraction of all mixtures was adjusted by weighing the components. The TDFRS experiments require a small amount of dye in the sample. In this work, all samples contained approximately $0.002 \mathrm{wt} \%$ of the dye Quinizarin (Aldrich). This amount ensures a sufficient optical modulation of the grating but is small enough to avoid convection and contributions of the dye to the concentration signal. Before each TDFRS experiment, approximately $2 \mathrm{ml}$ of the freshly prepared solution were filtered through $0.2 \mu \mathrm{m}$ filter (hydrophobic PTFE) into an optical quartz cell with $0.2 \mathrm{~mm}$ optical path length (Helma) which was carefully cleaned from dust particles before usage.

After each measurement we checked carefully by monitoring the change of the meniscus height in the two filling capillaries of the sample cell whether the volatile solvent evaporated during the measurement. The accuracy of this method is certainly better than $1 \%$. The total volume of the sample cell is in the order of $0.6 \mathrm{ml}$. Even for the $n$-decane $/ n$-pentane mixture with the lowest pentane content, the concentration change should be less than $\Delta x \approx \Delta c \approx 0.01$. 

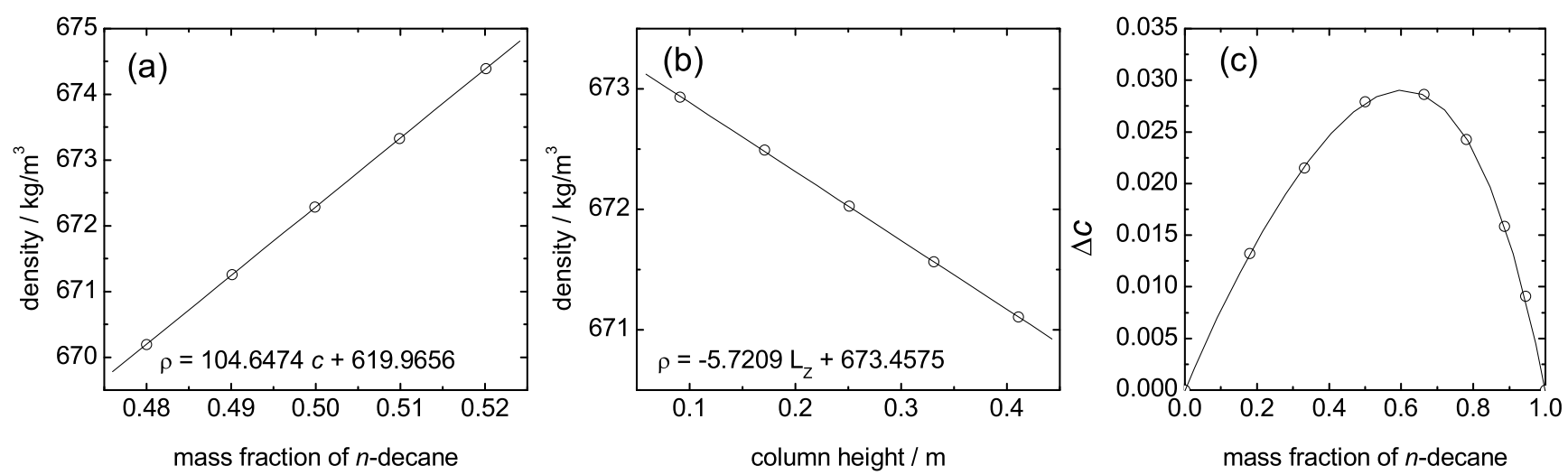

FIG. 1: (a) Density of the mixture $n$-decane $/ n$-pentane as function of the mass fraction around the concentration $c=0.5$ at $T=25^{\circ} \mathrm{C}$. (b) Density of the same mixture as function of the column height at $c=0.5$ and $T=25^{\circ} \mathrm{C}$. The results were obtained with the cylindrical TC. (c) Mass separation $\Delta c$ for $n$-decane $/ n$-pentane as function of the mass fraction of $n$-decane at $T=27^{\circ} \mathrm{C}$.

\section{B. Data analysis and set-up}

\section{Thermogravitational columns:}

The TC theory provides a relation between the stationary separation $\Delta c$ and the thermodiffusion coefficient $D_{T}$. For more details see Ref. [26]:

$$
\Delta c=-\frac{504 L_{z}}{g L_{x}^{4}} \frac{D_{T} \nu}{\alpha} c_{0}\left(1-c_{0}\right)
$$

Where $\alpha=-(1 / \rho)(\partial \rho / \partial c)$ is the thermal expansion coefficient, $\rho$ the density of the mixture with the initial mass concentration $c_{0}, \nu$ the kinematic viscosity and $g$ the gravity acceleration. $L_{z}$ is the height of the column, which is $500 \mathrm{~mm}$ for the cylindrical TC and 530 $\mathrm{mm}$ for the parallelepipedic TC. And $L_{x}$ is the gap between the two vertical walls, which is $1.000 \pm 0.005 \mathrm{~mm}$ for the cylindrical TC and $1.50 \pm 0.01 \mathrm{~mm}$ for the parallelepipedic TC. Just taking into account the uncertainty in the gap dimension $\left(L_{x}\right)$ leads to an relative systematic error in the order of $2 \%$ and $2.7 \%$ for the cylindrical and parallelepipedic TC.

The mass separation between the two ends of the column $\Delta c$ is determined from a calibration curve which relates mass fraction and density. In order to make the calibration, five mixtures with known concentration, close to the initial mass fraction $\left(c_{0} \pm 0.02\right)$ are prepared by weighting. The accuracy of the determined mass is $0.0001 \mathrm{~g}$. For the investigated 
TABLE I: Thermophysical properties of binary $n$-alkane mixtures with $n$-decane as first component. Chemical structure of the second component, mass fraction of $n$-decane $c$, density $\rho$, thermal expansion coefficient $\alpha$, mass expansion coefficient $\beta$, dynamic viscosity $\eta$, refractive index increment with concentration $(\partial n / \partial c)$ and temperature $(\partial n / \partial T)$.

\begin{tabular}{|c|c|c|c|c|c|c|c|}
\hline $\begin{array}{c}\text { second } \\
\text { component }\end{array}$ & $c$ & $\begin{array}{c}\rho / \\
\mathrm{kg} / \mathrm{m}^{3}\end{array}$ & $\begin{array}{c}\alpha / \\
10^{-3} \mathrm{~K}^{-1}\end{array}$ & $\beta$ & $\begin{array}{c}\eta / \\
\mathrm{m} \cdot \mathrm{Pa} \cdot \mathrm{s}\end{array}$ & $(\partial n / \partial c)$ & $\begin{array}{c}(\partial n / \partial T) / \\
10^{-3}\end{array}$ \\
\hline \multicolumn{8}{|c|}{$T=27^{\circ} \mathrm{C}$} \\
\hline \multirow{7}{*}{$\mathrm{C}_{5} \mathrm{H}_{12}$} & 0.945 & 718.461 & 1.069 & 0.1540 & 0.758 & - & - \\
\hline & 0.886 & 711.864 & 1.098 & 0.1571 & 0.690 & 0.05670 & -0.476 \\
\hline & 0.780 & 700.261 & 1.150 & 0.1568 & 0.586 & 0.05663 & -0.501 \\
\hline & 0.663 & 687.589 & 1.208 & 0.1555 & 0.478 & 0.05593 & -0.518 \\
\hline & 0.500 & 670.325 & 1.297 & 0.1571 & 0.403 & - & - \\
\hline & 0.332 & 652.835 & 1.399 & 0.1570 & 0.333 & 0.05388 & -0.519 \\
\hline & 0.180 & 637.718 & 1.495 & 0.1583 & 0.277 & - & - \\
\hline \multicolumn{8}{|c|}{$T=25^{\circ} \mathrm{C}$} \\
\hline $\mathrm{C}_{5} \mathrm{H}_{12}$ & \multirow{10}{*}{0.500} & 672.306 & 1.288 & 0.1571 & 0.399 & 0.05481 & -0.504 \\
\hline $\mathrm{C}_{6} \mathrm{H}_{14}$ & & 689.823 & 1.200 & 0.1032 & 0.470 & 0.03724 & -0.494 \\
\hline $\mathrm{C}_{7} \mathrm{H}_{16}$ & & 702.601 & 1.141 & 0.0660 & 0.563 & 0.02425 & -0.477 \\
\hline $\mathrm{C}_{8} \mathrm{H}_{18}$ & & 712.330 & 1.098 & 0.0394 & 0.656 & 0.01435 & -0.466 \\
\hline $\mathrm{C}_{14} \mathrm{H}_{30}$ & & - & - & - & - & -0.01723 & -0.434 \\
\hline $\mathrm{C}_{15} \mathrm{H}_{32}$ & & 745.446 & 0.974 & -0.0524 & 1.397 & - & - \\
\hline $\mathrm{C}_{16} \mathrm{H}_{34}$ & & 747.768 & 0.967 & -0.0588 & 1.515 & -0.02290 & -0.431 \\
\hline $\mathrm{C}_{17} \mathrm{H}_{36}$ & & 749.893 & 0.958 & -0.0645 & 1.634 & -0.02507 & -0.429 \\
\hline $\mathrm{C}_{18} \mathrm{H}_{38}$ & & 751.756 & 0.951 & -0.0698 & 1.778 & -0.02716 & -0.427 \\
\hline $\mathrm{C}_{20} \mathrm{H}_{42}$ & & 754.988 & 0.944 & -0.0781 & 2.102 & -0.03108 & -0.423 \\
\hline
\end{tabular}

mixtures we obtained always a linear relation between the density and the mass fraction. From the calibration curve the mass expansion coefficient $\beta=(1 / \rho)(\partial \rho / \partial c)$ is obtained. An example for the mixture $n$-decane $/ n$-pentane is shown in the figure $1 \mathrm{a}$.

We determine the stationary mass separation between the two ends of the column using 
the following expression:

$$
\Delta c=\frac{L_{z}}{\beta \rho} \frac{\partial \rho}{\partial z}
$$

where $\partial \rho / \partial z$ is the vertical density gradient along the TC. The density gradient $\partial \rho / \partial z$ is obtained from five samples which are equally distributed along the height of the TC. In all mixtures studied in this work the variation of the density with height is linear. A typical experimental result is shown in figure $1 \mathrm{~b}$.

The stationary state is determined by the following expression ${ }^{12}$ :

$$
t_{r}=\frac{9 !\left(L_{z} \nu\right)^{2} D}{\left(g \pi \alpha \Delta T L_{x}^{3}\right)^{2}}
$$

where $t_{r}$ is the relaxation time and $\Delta T$ is the applied temperature difference between the two vertical walls. $\Delta T$ has been adjusted to $6^{\circ} \mathrm{C}$, although in the stationary state the mass separation is independent of the applied temperature gradient. ${ }^{27}$ Typically the time for reaching the stationary state is 5 times the relaxation time. We have repeated each measurement at least 3 times and in one measurement we waited 15 times the relaxation time. All experimental results agreed with $2 \%$, which indicates that the chosen time, has been long enough to reach the stationary state.

Figure 1c shows the mass separation of the mixtures $n$-decane $/ n$-pentane at different initial mass fractions. The separation $\Delta c$ shows a maximum at a mass fraction of $n$-decane at $c=0.6$.

\section{TDFRS:}

The thermal diffusion behavior of the solutions was investigated by thermal diffusion forced Rayleigh scattering (TDFRS). A detailed description of the set-up can be found elsewhere. $^{28}$

The heterodyne diffraction signal $\zeta_{\text {het }}$ is evaluated by the equation,

$$
\zeta_{\text {het }}(t)=1+\left(\frac{\partial n}{\partial T}\right)^{-1}\left(\frac{\partial n}{\partial c}\right) S_{\mathrm{T}} c(1-c)\left(1-e^{-q^{2} D t}\right)
$$

with the refractive index increment with concentration at constant pressure and temperature $(\partial n / \partial c)$, the derivative of the refractive index with temperature at constant pressure and concentration $(\partial n / \partial T)$ and the collective diffusion coefficient $D$. 


\section{Density measurements}

The thermal expansion $\alpha$, the mass expansion $\beta$ and the density $\rho$ of all the mixtures have been measured with an Anton Paar DMA 5000 vibrating quartz U-tube densimeter. It has a reproducibility of $1 \cdot 10^{-6} \mathrm{~g} / \mathrm{cm}^{3}$ with a temperature accuracy of $0.001^{\circ} \mathrm{C}$. The sample volume needed to make one density measurement is roughly $1.5 \mathrm{ml}$. The thermophysical properties of all the mixtures studied in this work are shown in Table I.

\section{Viscosity measurements}

The dynamic viscosity has been determined by a HAAKE falling ball viscosimeter with an estimated accuracy of $\pm 1 \%$. The temperature stability is $\pm 0.1^{\circ} \mathrm{C}$. The volume needed to make one viscosity measurement is approximately $40 \mathrm{ml}$. The dynamic viscosity $\mu$ listed in Table I are the average of at least 8 individual measurements with typical standard deviation below $1 \%$.

\section{E. Refractive index increments}

An Anton Paar RXA 156 refractometer has been used to measure the refractive index increments with the mass concentration $(\partial n / \partial c)$ (see Table I). It has a repeatability of $2 \cdot 10^{-5}$ and the temperature accuracy is $\pm 0.01^{\circ} \mathrm{C}$. The volume needed to make one measurement is less than $1 \mathrm{ml}$. For all investigated temperatures and concentrations we find a linear dependence of the refractive index on concentration if the temperature is fixed or on temperature if the concentration is fixed. For all mixtures we determined the $(\partial n / \partial c)$ values. We would like to point out that the refractive index increments with concentration, which had been determined for the mixture $n$-decane $/ n$-pentane in the previous work ${ }^{13}$ by an Abbe refractometer agreed with the new values within the error bars.

For the TDFRS measurements for all mixtures except for the system $n$-decane $/ n$-pentane $(\partial n / \partial T)$ was directly measured by an interferometer. In the case of $n$-decane $/ n$-pentane $(\partial n / \partial T)$ the reliablity of the refractometer was better, because due to the long measurement time in the interferometer pentane evaporated partly, which lead to concentration changes during the measurement. The contrast factors $(\partial n / \partial c)$ and $(\partial n / \partial T)$ for two groups of mixtures are listed in Table I. 
TABLE II: Thermal diffusion coefficients for $n$-decane in $n$-pentane at $T=27^{\circ} \mathrm{C} . D_{\mathrm{T}}^{\mathrm{TDFRS}} \mathrm{old}_{\text {ond }}$ and $D_{\mathrm{T}}^{\mathrm{S}-\mathrm{NEMD}_{\text {c.v }} \text {. }}$ refer to experimental data and simulation results in the center-of-volume-reference frame, respectively. ${ }^{13} D_{\mathrm{T}}^{\mathrm{TC}}{ }^{\mathrm{T} a r a}, D_{\mathrm{T}}^{\mathrm{TC}}{ }^{\mathrm{T} 1}$ and $D_{\mathrm{T}}^{\mathrm{TDFRS}}$ have been measured in this work by parallelepipedic TC, cylindrical TC and TDFRS. For details see the text.

\begin{tabular}{|c|c|c|c|c|c|c|c|c|c|c|c|c|c|}
\hline$x$ & $c$ & \multicolumn{2}{|c|}{$\begin{array}{c}D_{\mathrm{T}}^{\mathrm{TDFRS}} \mathrm{old}_{\text {old }} \\
10^{-8} \mathrm{~cm}^{2} \mathrm{~s}^{-1} \mathrm{~K}^{-1} \\
\text { ( Ref. [13] ) }\end{array}$} & \multicolumn{2}{|c|}{$\mid \begin{array}{c}D_{\mathrm{T}}^{\mathrm{S}-\mathrm{NEMD}_{c . v}} / \\
10^{-8} \mathrm{~cm}^{2} \mathrm{~s}^{-1} \mathrm{~K}^{-1} \\
\quad \text { Ref. [13] ) }\end{array}$} & \multicolumn{3}{|c|}{$\mid \begin{array}{c}D_{\mathrm{T}}^{\mathrm{TC} \mathrm{para}_{\mathrm{p}}} / \\
10^{-8} \mathrm{~cm}^{2} \mathrm{~s}^{-1} \mathrm{~K}^{-1}\end{array}$} & \multicolumn{2}{|c|}{$\mid \begin{array}{c}D_{\mathrm{T}}^{\mathrm{TC}_{\mathrm{cyl}}} / \\
10^{-8} \mathrm{~cm}^{2} \mathrm{~s}^{-1} \mathrm{~K}^{-1}\end{array}$} & \multicolumn{3}{|c|}{$\mid \begin{array}{c}D_{\mathrm{T}}^{\mathrm{TDFRS}} / \\
10^{-8} \mathrm{~cm}^{2} \mathrm{~s}^{-1} \mathrm{~K}^{-1}\end{array}$} \\
\hline 0.10 & 0.180 & - & & - & & & - & & $11.99 \pm$ & 0.5 & & 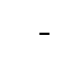 & \\
\hline 0.20 & 0.332 & $9.28 \pm$ & 0.75 & $13.30 \pm$ & 0.97 & 10.49 & \pm & 0.03 & $10.36 \pm$ & 0.5 & 10.81 & $1 \pm$ & 0.7 \\
\hline 0.34 & 0.180 & - & & - & & & - & & $9.37 \pm$ & 0.4 & & - & \\
\hline 0.50 & 0.663 & $7.54 \pm$ & 0.61 & $10.42 \pm$ & 2.34 & 8.76 & \pm & 0.03 & $8.67 \pm$ & 0.4 & 9.11 & \pm & 0.6 \\
\hline 0.64 & 0.780 & - & & - & & & - & & $7.56 \pm$ & & 8.11 & \pm & \\
\hline 0.80 & 0.886 & $7.18 \pm$ & 0.59 & $10.16 \pm$ & 1.50 & 6.76 & \pm & 0.02 & $6.92 \pm$ & 0.3 & 7.75 & \pm & 0.6 \\
\hline 0.90 & 0.945 & - & & - & & & - & & $7.02 \pm$ & & & - & \\
\hline
\end{tabular}

\section{RESULTS AND DISCUSSION}

\section{A. Thermal diffusion behavior of $n$-decane in $n$-pentane}

Figure 2 shows the thermal diffusion coefficient $D_{\mathrm{T}}$ for $n$-decane in $n$-pentane for several mass fractions of $n$-decane. In general $D_{\mathrm{T}}$ decays with increasing $n$-decane content. The measurements between the parallelepipedic and cylindrical thermogravitational columns agree typically better than 5\%. We estimated the error bars for the TC by error propagation taking into account the experimental uncertainties of the auxiluary quantities such as viscosity $(<1 \%)$, mass expansion $(<1 \%)$, thermal expansion $(<0.5 \%)$, variation of the density with height in the column (typically better than $2 \%$ and $3 \%$ for cylindrical and parallelepipedic TC, respecively) and geometrical parameters (typically better than $1 \%$ and $3 \%$ for cylindrical and parallelepipedic TC). The error bars for the TDFRS data correspond to one standard deviation of the mean for repeated measurements. The actual TDFRS data are systematically $5-11 \%$ higher than the TC data, but agree within the error bars. The highest deviation in comparison with the TDFRS data of $11 \%$ has been found for the lowest pen- 
tane content. This concentration is the one, which is most sensitive to the evaporation of pentane. The same absolute loss of pentane leads for this concentration to a much larger relative concentration change compared to concentrations with a higher pentane content. In both experiments a potential loss of pentane was carefully monitored as described in Sections II A 1 and II A 2, respectively. The expected changes in concentration are smaller than the symbol size.

In addition, the thermal diffusion coefficient of $n$-decane in $n$-pentane mixtures for different concentrations deviate less than $3 \%$ from the values obtained with another cylindrical column, ${ }^{29}$ which is an independent measurement by another group.

The old TDFRS measurements ${ }^{13}$ are systematically 10-20\% lower than the present TDFRS data and the deviation with the TC data are in the order of $5-15 \%$. The deviations between the two sets of TDFRS data can probably be explained by the fact that at that time the data had not been corrected by the so-called excitation function which accounts for time delays in the electrical switching of the Pockels cell. A detailed description of the procedure can be found in Ref. [28].

We compare also our new TC and TDFRS data with previous non-equilbrium molecular dynamic simulation results for the system $n$-decane/n-pentane by Perronace et al. ${ }^{13}$ (see Table II). The simulations have been carried out in the center-of-mass reference frame and the resulting transport coefficients have been transformed to the center-of-volume reference frame, which corresponds to the situation in the experiment. The statistical uncertainty of the simulations is in the order of $35 \%$, while the systematic deviations between experimental and simulation data are in the order of $15-40 \%$. For instance for the equimolar mixture $n$ decane/ $n$-pentane the data agree almost within the error bars.

\section{B. Thermal diffusion behavior of $n$-decane in various alkane at equal mass ratio}

Additionally we performed measurements for $n$-decane with various shorter and longer linear alkanes. The thermal diffusion and diffusion coefficients for $n$-decane in various alkanes with a mass fraction of $50 \%$ at $T=25^{\circ} \mathrm{C}$ are listed in Table III. For comparison we list also previous thermal diffusion data, which have also been obtained by a parallelepipedic TC but with different dimensions. ${ }^{15}$ The diffusion coefficients from the same reference ${ }^{15}$ have been determined by the open-end capillary (OEC) method..$^{30}$ 


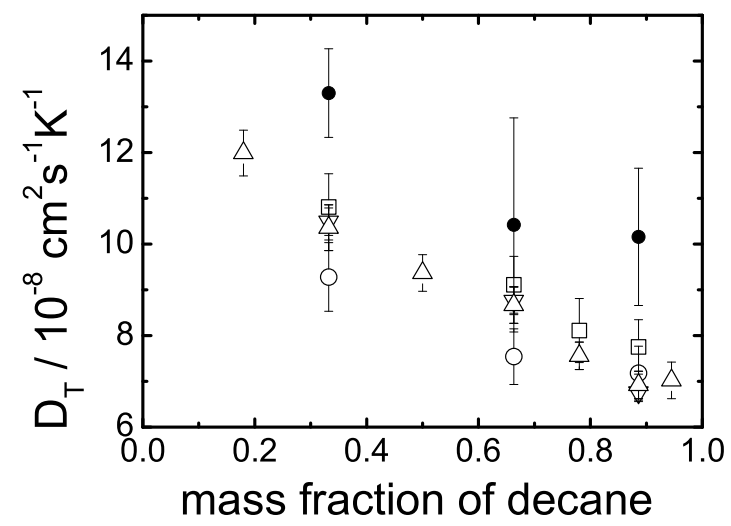

FIG. 2: Thermal diffusion coefficient $D_{\mathrm{T}}$ for $n$-decane in $n$-pentane in dependence of the mass fraction of $n$-decane obtained by a parallelepipedic TC $(\nabla)$, cylindrical TC $(\Delta)$ and TDFRS $(\square)$. For comparison we show also the previous experimental $(\bigcirc)$ and simulation results in the centerof-volume-reference frame $(\bullet) .{ }^{13}$

Figure 3(a) shows the thermal diffusion, diffusion and Soret coefficients for the measurement with the cylindrical TC and the TDFRS set-up as function of the molar mass of the second component. For comparison we also show the previous data by Leahy-Dios and Firoozabadi. ${ }^{15}$ As expected the thermal diffusion coefficient of $n$-decane in shorter alkane is positive, and therefore the $n$-decane goes towards the cold region, while it becomes negative when the mass of the second component becomes larger, which implies that $n$-decane migrates to the warm side. The agreement between the cylindrical TC and the TDFRS data is typically better than $5 \%$.

If we compare our data with recent data in the literature, ${ }^{15}$ we find deviations between 10-30\%. Compared to those previous measurements the TC used in this work allows a more accurate analysis of the mass separation between the top and the bottom of the TC due to the smaller gap and a better precision of the gap of $L_{x}=1.0 \pm 0.005 \mathrm{~mm}$ (c.f. II B 1). The TC used by Leahy-Dios and Firoozabadi ${ }^{15}$ had a gap of $1.6 \pm 0.02 \mathrm{~mm}$. This low precision of the gap dimensions causes an uncertainty of $5 \%$ in the determination of the thermal diffusion coefficient, not regarding the propagating errors due to uncertainties in the thermophysical properties, which are required to calculate the thermal diffusion coefficient (see Eqs. 2 and 3). For the TC used in this work the mass separation is 6.55 times greater than for the 
TABLE III: Thermal diffusion and diffusion coefficients for $n$-decane in various alkanes at $T=25^{\circ} \mathrm{C}$. In the first two columns the totals formula and the molecular weight of the second component are listed. $\quad D_{\mathrm{T}}^{\mathrm{TC}}$ and $D^{\mathrm{OEC}}$ refer to previous experimental data. ${ }^{15} D_{\mathrm{T}}^{\mathrm{TC}{ }_{c y l}}$ and $D_{\mathrm{T}}^{\mathrm{TDFRS}}$ have been measured in this work by cylindrical TC and TDFRS. Details are given in the text.

\begin{tabular}{|c|c|c|c|c|c|c|c|c|c|c|}
\hline \multirow{2}{*}{\begin{tabular}{|l} 
totals \\
formula \\
$\mathrm{C}_{5} \mathrm{H}_{12}$
\end{tabular}} & \multirow{2}{*}{\begin{tabular}{|c|}
$M /$ \\
$\mathrm{g} / \mathrm{mol}$ \\
72.15
\end{tabular}} & \multicolumn{2}{|c|}{$\begin{array}{c}D_{\mathrm{T}}^{\mathrm{TC}} / \\
10^{-8} \mathrm{~cm}^{2} \mathrm{~s}^{-1} \mathrm{~K}^{-1} \\
\text { Ref. [15] }\end{array}$} & \multirow{2}{*}{\begin{tabular}{|c}
$D^{\text {OEC }} /$ \\
$10^{-5} \mathrm{~cm}^{2} \mathrm{~s}^{-1}$ \\
Ref. $[15]$ \\
$2.50 \pm 0.20$
\end{tabular}} & \multicolumn{2}{|c|}{$\begin{array}{c}D_{\mathrm{T}}^{\mathrm{TC}_{\mathrm{cyl}}} / \\
10^{-8} \mathrm{~cm}^{2} \mathrm{~s}^{-1} \mathrm{~K}^{-1}\end{array}$} & \multicolumn{2}{|c|}{$\mid \begin{array}{c}D_{\mathrm{T}}^{\mathrm{TDFRS}} / \\
10^{-8} \mathrm{~cm}^{2} \mathrm{~s}^{-1} \mathrm{~K}^{-1}\end{array}$} & \multicolumn{2}{|c|}{$\begin{array}{c}D^{\text {TDFRS }} / \\
10^{-5} \mathrm{~cm}^{2} \mathrm{~s}^{-1} \mathrm{~K}^{-1}\end{array}$} \\
\hline & & $9.64 \pm$ & 0.19 & & $9.24 \pm$ & 0.4 & $9.59 \pm$ & 0.33 & $3.19 \pm$ & 0.04 \\
\hline $\mathrm{C}_{6} \mathrm{H}_{14}$ & 86.18 & $7.79 \pm$ & 0.21 & \pm & $6.71 \pm$ & 0.3 & $6.51 \pm$ & 0.29 & $2.69 \pm$ & 0.07 \\
\hline $\mathrm{C}_{7} \mathrm{H}_{16}$ & 100.20 & $5.99 \pm$ & 0.56 & $23 \pm 0.11$ & $4.37 \pm$ & 0.3 & $5.00 \pm$ & 0.42 & $2.61 \pm$ & 0.20 \\
\hline $\mathrm{C}_{8} \mathrm{H}_{18}$ & 114.23 & $3.86 \pm$ & 0.14 & $.84 \pm 0.18$ & - & & $3.51 \pm$ & 0.53 & $2.57 \pm$ & .27 \\
\hline${ }_{12} \mathrm{H}_{26}$ & 170.33 & $-1.85 \pm$ & 0.41 & $10 \pm 0.12$ & - & & - & & - & \\
\hline${ }_{1} \mathrm{H}_{30}$ & 198.39 & $-2.65 \pm$ & 0.22 & $0 \pm 0.22$ & - & & $-1.85 \pm$ & 0.46 & $0.89 \pm$ & 0.24 \\
\hline${ }_{5} \mathrm{H}_{32}$ & 212.42 & - & & - & $-2.39 \pm$ & 0.15 & - & & - & \\
\hline $\mathrm{C}_{16} \mathrm{H}_{34}$ & 226.44 & $-3.35 \pm$ & 0.09 & $0.68 \pm 0.07$ & $-2.47 \pm$ & 0.15 & $-2.58 \pm$ & 0.29 & $0.84 \pm$ & 0.12 \\
\hline $\mathrm{C}_{17} \mathrm{H}_{36}$ & 240.47 & - & & - & $-2.53 \pm$ & 0.15 & $-2.59 \pm$ & 0.17 & $0.75 \pm$ & 0.07 \\
\hline $\mathrm{C}_{18} \mathrm{H}_{38}$ & 254.49 & - & & - & $-2.56 \pm$ & 0.15 & $-2.69 \pm$ & 0.17 & $0.73 \pm$ & 0.05 \\
\hline $\mathrm{C}_{20} \mathrm{H}_{42}$ & 282.55 & $-2.31 \pm$ & 0.04 & $0.47 \pm 0.01$ & $-2.65 \pm$ & 0.15 & $-2.86 \pm$ & 0.12 & $0.65 \pm$ & 0.03 \\
\hline
\end{tabular}

TC used in Ref. [15]. Therefore, the difference in the thermal diffusion coefficient, $D_{\mathrm{T}}$, determined with those two columns (Ref. [15] and this work) becomes larger for mixtures with a small mass separation. This tendency can be observed for the mixtures $n$-decane $/ n$ heptane and $n$-decane/ $n$-hexadecane. In contrast to the previous measurements we could not confirm the non-monotonic trend of the thermal diffusion coefficient with increasing molecular weight of the second component. Both measurement techniques, TC and TDFRS indicate that $D_{\mathrm{T}}$ becomes constant and therefore independent of the molecular weight of the second component. This is also the behavior, which has been observed for infinite diluted solutions of polymers. ${ }^{31,32}$

Figure 3(b) shows a comparison between the diffusion coefficients determined in the previous study by the open-end-capillary (OEC) technique and the present TDFRS study. In general the OEC data are systematically lower than for the TDFRS data. Typically one 


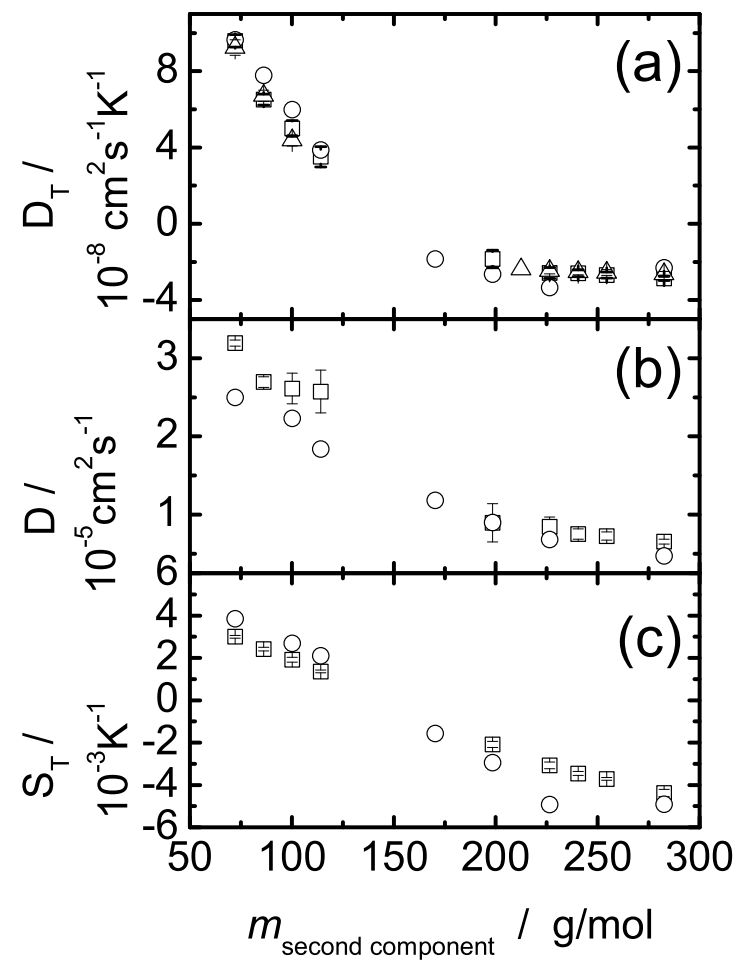

FIG. 3: Thermal diffusion coefficient $D_{\mathrm{T}}$, diffusion coefficient $D$ and Soret coefficient $S_{\mathrm{T}}$ for $n$ decane in different alkanes in dependence of the molar mass of the second alkane component measured by TC $(\triangle)$ and TDFRS $(\square)$. For comparion we show also the data $(\bigcirc)$ obtained in the previous work by Leahy-Dios and Firoozabadi. ${ }^{15}$ All measurements have been performed for $c=0.5$ at a temperature $T=25^{\circ} \mathrm{C}$.

finds deviations larger than $30 \%$ in the entire molar mass range of the second compound. Typically the agreement is better for the higher molar mass components than the lower molecular weight components, therefore evaporation problems might be responsible for these discrepancies.

In Figure 3c we compare the Soret coefficients determined by the TDFRS method with the previous results by Leahy-Dios and Firoozabadi. ${ }^{15}$ Both studies show a decay of the Soret coefficient with increasing molecular weight of the second component. While the previous data seem to show a vague minimum, our data do not confirm this tren. The magnitude of Soret coefficient calculated ${ }^{15}$ from the thermal diffusion coefficient determined by the TC method and diffusion coefficients measured with the OEC method is always larger than the 
$S_{\mathrm{T}}$ values determined in the TDFRS experiment. The deviations are typically in the order of $20-40 \%$.

\section{CONCLUSION}

In this paper, we studied systematically binary alkane mixtures by two different techniques, a convective method the thermogravitational column (TC) (paralelepipedic and cylindrical configurations) technique and a non-convective method thermal diffusion forced Rayleigh scattering (TDFRS). In general we found a very good agreement between these two methods. Nevertheless we found some discrepancies with data published in the literature. The observed disagreement between the published $\operatorname{TDFRS}^{13}$ data for the mixture $n$-decane/ $n$-pentane is probably caused by an improved data analysis algorithm, which accounts for finite rising times and slow drifts of the electro-optic devices used in the experiment. Additionally we found discrepancies with recently published TC data. ${ }^{15}$ We assume that the reason for the disagreement of the recent TC data is the larger gap $L_{x}$ in the previously used cell ${ }^{15}$ compared to the cells used in this work. The larger gap decreases the accuracy of determinig the mass separation between the two ends of the TC. This is especially important for the mixtures of decane, with the higher alkanes. Neither our TC nor our TDFRS measurements showed the upward trend of the thermal diffusion coefficient, $D_{\mathrm{T}}$, for the higher alkanes, which was recently observed. ${ }^{15}$ Our measurements seem to indicate that the thermal diffusion coefficient becomes independent of the molar mass of the second component. This issue could certainly be further investigated by molecular simulations as it has been done for alkane mixtures and other small molecules. ${ }^{13,33}$

\section{Acknowledgments}

The authors would like to thank Dr. Hartmut Kriegs for his experimental assistance. Prof. J.K. Platten for yield us the parallelepipedic TC of the University of Mons and Profs. J.A. Madariaga and C. Santamaría for the discussion of the experimental results in the mixtures of n-pentane-n-decane. This work was partially supported by the Deutsche Forschungsgemeinschaft grant Wi 1684, the Basque Government grant BFI05.449 and the 
projects GOVSORET (PI2008-14) and TESBLUR (CTQ2005/09389/C02/01/PPQ).

* pblanco@eps.mondragon.edu;

$\dagger$ p.polyakov@fz-juelich.de; http://www.fz-juelich.de/iff/personen/P.Polyakov/

$\S$ mbouali@eps.mondragon.edu;

** s.wiegand@fz-juelich.de; http://www.fz-juelich.de/iff/personen/S.Wiegand/

1 P. Costeseque, D. Fargue, and P. Jamet, in Thermal nonequilibrium phenomena in fluid mixtures, edited by W. Köhler and S. Wiegand (Springer, Berlin, 2000), Lecture Notes in Physics, pp. $389-427$.

2 K. Ghorayeb and A. Firoozabadi, SPE Journal 5, 158 (2000).

3 K. Ghorayeb, A. Firoozabadi, and T. Anraku, SPE Journal 8, 114 (2003).

4 W. Köhler and R. Schäfer, in New Developments in Polymer Analytics Ii, edited by M. Schmidt (Springer, Berlin, 2000), vol. 151 of Advances in Polymer Science, pp. 1-59.

5 W. Köhler and S. Wiegand, eds., Thermal nonequilibrium phenomena in fluid mixtures, vol. LNP584 of Lecture Note in Physics (Springer, Berlin, 2002), 1st ed.

6 J. Platten, M. Bou-Ali, and J. Dutrieux, J. Phys. Chem. B B 2003, 11763 (2003).

7 S. Wiegand, J.Phys.:Condens. Matter 16, R357 (2004).

8 C. Debuschewitz and W. Köhler, Phys. Rev. Lett, 87, art. no. (2001).

9 G. Wittko and W. Köhler, J. Chem. Phys. 123, 014506 (2005).

10 K. J. Zhang, M. E. Briggs, R. W. Gammon, and J. V. Sengers, J. Chem. Phys. 104, 6881 (1996).

11 W. Köhler and B. Müller, J. Chem. Phys. 103, 4367 (1995).

12 M. M. Bou-Ali, O. Ecenarro, J. A. Madariaga, C. M. Santamaría, and J. J. Valencia, J. Phys.:Condens. Matter 10, 3321 (1998).

13 A. Perronace, C. Leppla, F. Leroy, B. Rousseau, and S. Wiegand, J. Chem. Phys. 116, 3718 (2002).

14 P. Blanco, M. Bou-Ali, J. Platten, J. Madariaga, P. Urteaga, and C. Santamaría, J. Non-Equilib. Thermodyn. 32, 309 (2007).

15 A. Leahy-Dios and A. Firoozabadi, J. Phys. Chem. B 111, 191 (2007).

16 H. Korsching, Z. Naturf. a 29, 1914 (1974). 
17 H. Korsching, Z. Naturf. a 24, 444 (1969).

18 J. Demichowicz-Pigoniowa, M. Mitchell, and H. Tyrrell, . Chem Soc. A - Inorg. phys. Theor. 2, 307 (1971).

19 O. Ecenarro, J. A. Madariaga, J. Navarro, C. M. Santamaría, J. A. Carrion, and J. M. Saviron, J.Phys.:Condens. Matter 2, 2289 (1990).

20 D. J. Trevoy and H. G. Drickamer, J. Phys. Chem. 17, 1120 (1949).

21 P. Polyakov, J. Luettmer-Strathmann, and S. Wiegand, J. Phys. Chem. B 110, 26215 (2006).

22 J. K. Platten, M. M. Bou-Ali, P. Costeseque, J. F. Dutrieux, W. Kohler, C. Leppla, S. Wiegand, and G. Wittko, Philos. Mag. 83, 1965 (2003).

23 M. G. Gonzalez-Bagnoli, A. A. Shapiro, and E. H. Stenby, Philos. Mag. 83, 2171 (2003).

24 M. C. dos Ramos and F. J. Blas, J. Phys. Chem. B 109, 12145 (2005).

25 M. Costas and D. Patterson, Thermochimica Acta 120, 161 (1987).

26 J. F. Dutrieux, J. K. Platten, G. Chavepeyer, and M. M. Bou-Ali, J. Phys. Chem. B 106, 6104 (2002).

27 P. Urteaga, M. Bou-Ali, J. Madariaga, C. Santamaría, P. Blanco, and J. Platten (Mondragon Unibertsitateko Zerbitzu Editoriala, 2006), pp. 449-458.

28 H. Ning, R. Kita, H. Kriegs, J. Luettmer-Strathmann, and S. Wiegand, J. Phys. Chem. B 110, $10746(2006)$.

29 Private communication: J.A. Madariaga and C. Santamaría, University Bilbao, University of Basque Country.

30 J. S. Anderson and K. Saddington, J. Chem. Soc. 5, 381 (1949).

31 M. E. Schimpf and J. C. Giddings, Macromolecules 20, 1561 (1987).

32 J. Rauch and W. Köhler, Macromolecules 38, 3571 (2005).

33 P. Polyakov, M. Zhang, F. Müller-Plathe, and S. Wiegand, J. Chem. Phys. 127, 014502 (2007). 